\title{
Factors affecting reorientation of hydraulically induced fracture during fracturing with oriented perforations in shale gas reservoirs
}

Qing-Chao Li

School of Energy Science and Engineering, Henan Polytechnic University, Jiaozuo, Henan 454000, China.

School of Petroleum Engineering, China University of Petroleum (East China), Qingdao, Shandong 266580, China.

liqingchao2020@hpu.edu.cn.b16020053@s.upc.edu.cn, bttp:/ / orcid.org/0000-0001-7373-4046

Liang Zhou

Well Testing Branch, CNPC Bobai Drilling Engineering Company Limited, Langfang, Hebei 065007, China.

zhouliang8@cnpc.com.cn

Zhi-Min Li

No.3 Drilling Engineering Company, CNPC Bohai Drilling Engineering Company Limited, Tianjin 300280, China.

libimin@.mpc.com.cn

Zhen-Hua Liu

Oil Production Plant No.2, Petrochina Changqing Oilfield Company, Qingcheng, Gansu 745100, China.

liushenhua3186@163.com

Yong Fang

Well Testing Branch, CNPC Bohai Drilling Engineering Company Limited, Langfang, Hebei 065007, China.

fang_yong@mpc.com.cn

Lei Zhao

No.4 Drilling Engineering Branch Company, CNPC Bohai Drilling Engineering Company Limited, Renqiu, Hebei 062550, China.

zhaolei9@.mpc.com.cn

Ying Han*

School of Energy Science and Engineering, Henan Polytechnic University, Jiaozuo, Henan 454000, China.

byhpu@hpu.edu.cn

ABSTRACT. Hydraulic fracturing with oriented perforations is an effective technology for gas development from shale reservoirs. However, fracture reorientation during fracturing operation can affect the fracture conductivity and hinder the effective production of shale gas. In addition, factors such as perforation azimuth, in-situ stresses, fracturing fluid viscosity and injection rate can affect fracture reorientation during fracturing operation, and the first

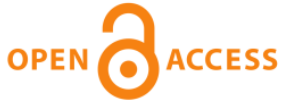

Citation: Li, Q.C., Zhou, L., Li, Z.-M.-, Liu, Z.-H., Fang., Y., Zhao, L., Han., Y., Factors affecting fracture reorientation during fracturing operation with oriented perforations in shale gas reservoirs, Frattura ed Integrità Strutturale, 58 (2021) 1-20. 
three factors are controllable factors. In the present work, a numerical simulation model for investigating fracture reorientation during fracturing with oriented perforations was established, and it was verified to be suitable for all investigations in this paper. Based on this simulation model, factors affecting both initiation and reorientation of the hydraulically induced fractures were investigated. The investigation results show that the fluid viscosity has little effect on initiation pressure of hydraulically induced

Received: 11.03 .2021 Accepted: 03.07.2021 Published: 01.10 .2021

Copyright: (C) 2021 This is an open access article under the terms of the CC-BY 4.0, which permits unrestricted use, distribution, and reproduction in any medium, provided the original author and source are credited. fracture during fracturing operation, and the initiation pressure is mainly affected by perforation azimuth, injection rate and the stress difference. Moreover, the investigation results also show that perforation azimuth and difference between two horizontal principal stresses are the two most important factors affecting fracture reorientation. Based on the investigation results, the optimization of fracturing design can be achieved by adjusting some controllable factors. However, the regret is that the research object herein is a single fracture, and the interaction between fractures during fracturing operation needs to be further explored.

KEYWORDS. Hydraulic fracturing; Oriented perforation; Fracture initiation; Fracture reorientation; Fracture propagation; Shale reservoir.

\section{INTRODUCTION}

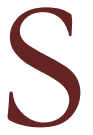

hale is the fragile and fine grain sedimentary layer that is composed of clastic particles with particle size less than $6.35 \times 10^{-5} \mathrm{~m}$, clay and organic matter [1]. According to U.S. Energy Information Administration (EIA), the global technically recoverable shale gas resources are $206.68 \times 10^{12} \mathrm{~m}^{3}$ by 2013 , and China has the largest recoverable reserves all over the world [2]. Moreover, the EIA predicts that shale gas will be the main driving force for increase of global natural gas production in the future. By 2040, the average daily production of shale gas is expected to be four times that of 2015 , reaching $4.76 \times 10^{9} \mathrm{~m}^{3}$ [3]. Therefore, although tight shale formations have been generally considered as the caprock of oil and gas reservoirs, they have received increasing attention as unconventional reservoir in recent years. However, shale reservoirs generally have lower permeability (usually between $1.0 \times 10^{-21} \mathrm{~m}^{2}$ and $1.0 \times 10^{-19} \mathrm{~m}^{2}$ ), and belong to ultra-low permeability reservoirs [4]. Hydraulic fracturing operations are generally considered to be effective measures to stimulate the physical properties of shale reservoirs, increasing natural gas production [5, 6]. Perforations around wellbore region can effectively reduce the initiation pressure that is needed to overcome in hydraulic fracturing operations, which is conducive to the initiation of hydraulically induced fractures [7-9]. Accordingly, hydraulic fracturing with oriented perforations has become an effective measure to stimulate shale reservoir. Ideally, to ensure the high fracture conductivity, the direction of perforation should be consistent with the direction of the maximum horizontal main stress. In fact, the geologic conditions of formation are often complicated and it is difficult to accurately determine the direction of the maximum horizontal principal stress $\sigma_{H}[7,10]$.

As shown in Fig.1A, stress concentration at the perforation tip due to injection of fracturing fluid results in the microhydraulically-induced fracture at the beginning of fracturing operation. As the fracturing fluid continues to be injected, the micro-fracture will propagate along the initial perforation for a certain distance (see Fig.1B). Then, fracture reorientation will occur if there is an angle between the perforation and the maximum horizontal principal stress (Fig.1C). The parameter $L$ in Fig.1C is defined as reorientation radius herein, which is used for describing fracture reorientation. In addition, the bending fractures formed during hydraulic fracturing will lead to retention of proppant in the reorientation position (see Fig.1D), which brings difficulty to the transport of proppant within fracture. Therefore, in-depth investigation on the reorientation of hydraulically induced fractures during hydraulic fracturing operation with oriented perforations is of great importance for the design and optimization of hydraulic fracturing in oilfields. At present, most investigations on hydraulic fracturing technology mainly focus on the analysis of post-fracturing productivity. In comparison, there are fewer studies on the behavioral evolution of fractures during fracturing. Recently, considerable advancements have already been made in behavior evolution of hydraulically induced fractures numerically and/or 
experimentally during hydraulic fracturing operations. Li et al. [11] numerically investigated factors affecting fracture propagation during the multi-cluster staged fracturing for shale reservoir using cohesive elements with ABAQUS FEM software. The investigation reveals that the cluster spacing between the adjacent hydraulic-induced fractures is the most important factor. Chang et al. [12] carried out a series of laboratory experiments to investigate the effectiveness of oriented perforation fracturing, and it showed that the fractures formed by oriented perforation fracturing technology tend to stimulate more reservoir volume. Zhu et al. [13] studied the factors affecting initiation pressure of unconventional reservoirs with a finite element model of hydraulic-induced fracture for the cased wells with the oriented perforations. $\mathrm{Li}$ et al. [14] analyzed the reorientation mechanism of hydraulically induced fracture with the coupling finite element model, and the investigation results showed that difference between the maximum and the minimum horizontal principal stresses affects the fracture morphology large. Although these investigations are particularly useful and helpful, there is a lack of detailed research on factors affecting reorientation of fractures during hydraulic fracturing operations with oriented perforation in shale reservoirs. In other words, investigation on the fracture reorientation during reservoir stimulation through hydraulic fracturing is not deep enough. Therefore, it is important and necessary to conduct relevant research.
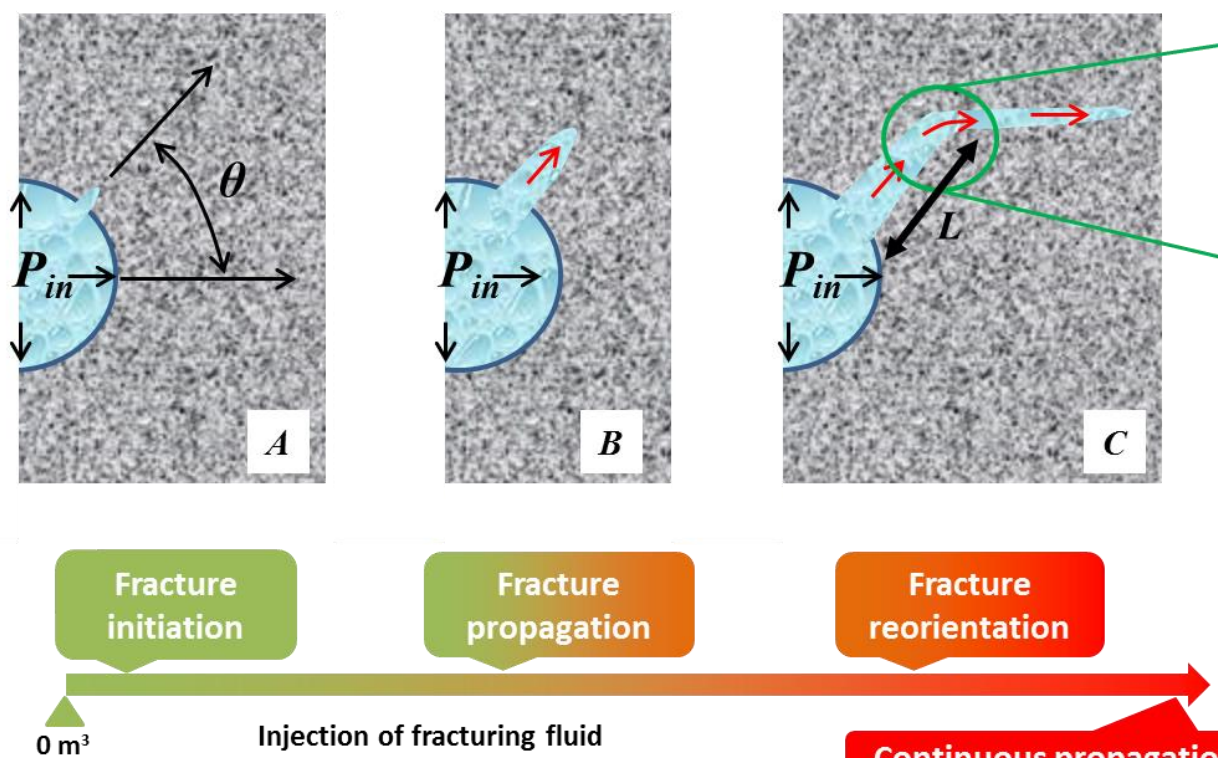

initiation
Fracture

propagation
Fracture

reorientation

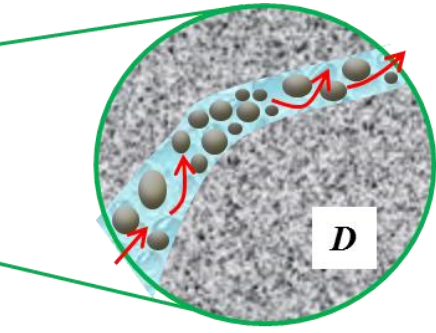

Fracturing Fluid

\section{Proppant}

Formation

\section{$P_{\text {in }}$ Injection Pressure}

\section{$\boldsymbol{\theta}$ Azimuth}

\section{Borehole}

Figure 1: Schematic of fracture reorientation during hydraulic fracturing operation with oriented perforations. A: fracture initiation; B: fracture propagation; C: fracture reorientation; D: proppant retention within fracture.

In addition, the interaction between fractures during fracturing operation is also an important factor affecting the final fracture morphology in reservoir. Therefore, in-depth analysis of the interaction between fractures is valuable for understanding the formation mechanism of complex fracture network during the fracturing operation. Up till now, some progress has been made by so many scholars in this area. However, current investigations focus on the interaction between natural fractures and hydraulic fractures during fracturing operation, rather than interaction between hydraulically induced fractures. Zhou et al. [15] analyzed crack coalescence in rocks with defects by uniaxial compression experiments and found that crack coalescence can occur in nearly all samples, but the mechanism is different for different types of rocks. Yu et al. [16] numerically analyzed the interaction between fractures during fracturing in tight sandstone reservoir. It was found that obvious interaction occurs between hydraulically induced fractures, and the reservoir pressure is the dominant factor affecting the interaction between fractures. Zhang et al. [17] analyzed factors affecting propagation of natural fracture by XFEM method, it is found that natural fracture propagates easily with the decrease of dip angle and stress difference. Arash [18] investigated the effect of natural fracture on propagation of hydraulically induced fractures, and the investigation results show that interaction between natural fracture and hydraulically induced fracture is the key condition resulting in complex fracture network. Nevertheless, considering that interaction between hydraulic fractures is not the focus of the present work, so related investigation is not carried out herein. In the present work, the coupled finite element model (FEM) used for investigating reorientation of the hydraulically induced fracture in shale reservoirs was developed by using the extended finite element method (XFEM). In this coupled model, some important aspects in the 
hydraulic fracturing operations (such as injection of fracturing fluid, fluid flow in hydraulically induced fractures and fracture reorientation) were considered. Based on this, factors affecting fracture reorientation during fracturing in shale reservoirs are then studied, regarding fracture initiation pressure and reorientation radius as the research target. The study in this paper will provide reference for fracturing design of unconventional oil and gas reservoirs.

\section{ELEMENTARY THEORY FOR HYDRAULIC FRACTURING BY XFEM}

$\mathrm{S}$ hale reservoirs are generally heterogeneous and anisotropic, which brings difficulties to practical research [19]. To highlight the research focus, the research model for investigating fracture reorientation in shale reservoirs is assumed to be a homogeneous, isotropic 2D plane strain model. Furthermore, it is considered that the fracture propagation is quasi-static and there is no fluid hysteresis within fractures. Finally, the incompressible Newton fracturing fluid is injected into the wellbore at a constant flow rate during fracturing. Therefore, in-depth study of fracture reorientation in hydraulic fracturing process needs to thoroughly understand the basic theories of seepage mechanics, rock mechanics and damage mechanics involved in the process. In this section, the elementary theories were presented.

\section{Stress balance equation of rock in shale reservoir}

Rock deformation occurs under the dual action of the in-situ stresses and the fluid pressure during fracturing. Weak form is the ultimate equation form for solving multi-field coupling problems by using finite element method. Therefore, the weak form of equations for both the seepage field (pore pressure) and the deformation field (stress and displacement) were obtained herein.

The weak form of stress balance equation can be expressed by Eqn. (1) when seepage in porous media of shale reservoir was considered [20, 21].

$$
\int_{V}\left(\boldsymbol{\sigma}-p_{w} \mathbf{I}\right): \delta \varepsilon d V=\int_{S} \mathbf{t} \cdot \delta \mathbf{u} d S+\int_{V} \mathbf{f} \cdot \delta \mathbf{u} d V
$$

where, $\boldsymbol{\sigma}$ is the effective stress, $\mathrm{MPa}$; $\mathbf{f}$ is the unit body force, $\mathrm{MPa} ; \mathrm{t}$ is the unit surface force, $\mathrm{MPa} ; p_{w}$ is the fluid pressure at the fracture, $\mathrm{MPa} ; \delta \boldsymbol{\varepsilon}$ is the virtual stain, dimensionless; $\delta \mathbf{u}$ is the virtual displacement, $\mathrm{m} ; d V$ is the volume of the micro-element, $\mathrm{m}^{3}$; and $d S$ is the area of the micro-element, $\mathrm{m}^{2}$.

Seepage flow equation in shale gas reservoir

Simulation of fluid seepage in shale reservoir can be realized by applying pore pressure at each node and then applying the boundary condition of pore pressure at a certain boundary. The law of mass conservation is the law that all physical processes follow. Therefore, the mass conservation equation of fracturing fluid in porous medium can be written as $[22$, 23]

$$
\frac{d}{d t}\left(\int_{V} \rho_{w} \varphi d V\right)+\int_{S} \rho_{w} \varphi \mathbf{n} \cdot \mathbf{v} d S=0
$$

where, $\rho_{w}$ is the density of fracturing fluid, $\mathrm{kg} / \mathrm{m}^{3} ; \varphi$ is the porosity, dimensionless; $\mathbf{n}$ is the normal vector of surface $S$, dimensionless.

At present, only single-phase incompressible seepage can be properly realized in ABAQUS software, and the calculation of complex multi-phase seepage cannot be achieved. Just as Eqn. (3), the seepage of fracturing fluid in shale reservoir is assumed to satisfy Darcy's law [21].

$$
\mathbf{v}=-\frac{1}{\varphi g \rho_{w}} \mathbf{k} \cdot d p
$$

where, $\mathbf{v}$ is the seepage velocity, $\mathrm{m} / \mathrm{s} ; k$ is the permeability of shale reservoir, $\mathrm{m}^{2} ; g$ is gravity acceleration, $9.8 \mathrm{~m} / \mathrm{s}^{2} ; d p$ is pressure difference between two ends of micro-element, MPa. 
Initiation and propagation of bydraulically induced fracture

The constitutive model of elements used for simulating fracture initiation satisfies the traction-separation criteria. That is to say, the constitutive relationship of elements within the investigation model herein is linear elastic before damage, and its stiffness drops to zero when the damage occurs. Up till now, a variety of different damage criteria (such as the maximum principal stress and the maximum principal strain criterion) have been embedded in the ABAQUS finite element software [11, 24]. Among them, the maximum stress criterion has been proved to be more effective and accurate [24]. Therefore, in this paper, the maximum principal stress criterion shown in Eqn. (4) is used as the damage criterion [25].

$$
f=\left\{\frac{\sigma_{\max }}{\sigma_{\max }^{0}}\right\}
$$

where, $\sigma_{\max }^{0}$ and $\sigma_{\max }$ are the critical maximum principal stress and the maximum principal stress respectively, MPa. Once the principal stress criterion was adopted, the critical maximum principal stress should be given, and the element damage begins to occur when the maximum principal stress $\sigma_{\max }$ exceeds the critical maximum principal stress $\sigma_{\max }^{0}$.

The damage evolution of the unit follows the Benzeggagh-Kenane criteria $[25,26]$ shown in the following equation

$$
G_{n c}+\left(G_{s c}-G_{n c}\right)\left(\frac{G_{S}}{G_{T}}\right)^{\eta}=G_{C}
$$

where, $G_{n c}, G_{s c}, G_{S}$ and $G_{T}$ are the normal critical energy release rate, tangential critical energy release rate, the first tangential fracture energy release rate and the second tangential fracture energy release rates respectively, $\mathrm{MPa} \cdot \mathrm{m} ; \eta$ is a constant, 2.284 .

\section{Fluid flow in fracture during fracturing}

Fluid flow in fracture can be divided into the normal flow and the tangential flow. The tangential flow ensures the continuous propagation of fracture during fracturing, and the following Cubic-Law can be adopted to describe the tangential flow in hydraulically induced fracture.

$$
q=-\frac{d^{3}}{12 \mu} \nabla p
$$

where, $q$ is the fluid flow required for $1 \mathrm{~m}$ of fracture propagation, $\mathrm{m}^{3} ; d$ is the fracture width, $\mathrm{m} ; \boldsymbol{\mu}$ is the fluid viscosity, $\mathrm{Pa} \cdot \mathrm{s}$.

Normal fluid flow within the hydraulically induced fracture results in the leak-off of fracturing fluid, and the leak-off of fracturing fluid from fracture into reservoir is defined as

$$
\mathbf{v}_{\text {leak-off }}=C_{\text {leak-off }}\left(p_{w}-p_{\text {Surf }}\right)
$$

where, $\mathbf{v}_{\text {leak-off }}$ is the leak-off velocity, $\mathrm{m} / \mathrm{s} ; C_{\text {leak-off }}$ is the leak-off coefficient, $\mathrm{m} /(\mathrm{MPa} \cdot \mathrm{s}) ; p_{\text {Surf }}$ is the pore pressure in shale reservoir adjacent to the fracture surfaces, $\mathrm{MPa}$.

\section{NUMERICAL MODELING OF SINGLE FRACTURE REORIENTATION}

\section{Model geometry and mesh generation}

Ithough the establishment of simulation model is the basic for investigation of fracture reorientation during 1 fracturing operation, a series of assumptions need to be made before the model is constructed. Firstly, shale Secondly, only single-phase seepage of fracturing fluid occurs in shale, and it satisfies Darcy's law. Moreover, shale is 
assumed to be elastic and its plastic failure during fracturing is ignored. Finally, wellbore used for shale gas production and fracturing operation is a vertical one (see Fig.2A).

Based on these assumptions, a 2D plane strain model for investigating fracture reorientation during hydraulic fracturing with oriented perforations in shale reservoirs is established with ABAQUS finite element software (see Fig.2). Therefore, only the maximum and the minimum horizontal principal stress exist within the $2 \mathrm{D}$ simulation model before simulation. As shown in Fig.2B, the investigation model is a full-size square model, and its side length is $200 \mathrm{~m}$. Generally speaking, the half-length of fractures during fracturing operation is within 100 meters [11]. Therefore, the model size in this paper is sufficient to avoid the influence of boundary effects on the simulation results [11, 27-29]. Moreover, the borehole with a radius of $0.2 \mathrm{~m}$ is located in the center of the simulation model. As can be seen from Fig.2A and Fig.2B, the simulation area "abcd" corresponds to a plane in shale reservoir that is perpendicular to the wellbore axis.

In order to improve the simulation accuracy, the element size at the outer boundaries is 25 times as large as that around wellbore (see Fig.2B and Fig.2C), and the reservoir model is finally discretized into 17,500 CPE4P elements. The CPE4P elements can realize coupling analysis of fracturing fluid seepage and borehole deformation in simulation of hydraulic fracturing. Another important reason for meshing in this way is that both the initiation and propagation of fractures mainly occur in the near-wellbore region around wellbore.

As can be seen in Fig.2C, two perforations are designed centrosymmetrically in different azimuth angles around borehole herein, and the perforation depth is $0.50 \mathrm{~m}$. In the model, reservoir and two perforations are three separate parts, and the perforations should be discretized separately during simulation. Therefore, two centrosymmetrical perforations around wellbore are discretized into 10 T2D2 elements and interact with the reservoir elements. During simulation with this model, when the pressure in perforation reaches reservoir strength, the fracture will initiate at the perforation tip.

\begin{tabular}{|c|c|c|}
\hline Load type & Objects & Type and value \\
\hline Fluid injection & Two injection nodes in Fig.2C & Injection rate $Q=10 \mathrm{~m}^{3} / \mathrm{min}$ \\
\hline \multirow{5}{*}{ Boundary condition } & Boundary $\mathrm{ab}$ and $\mathrm{cd}$ & Displacement $U 1=0$ \\
\hline & Boundary bc and da & Displacement $U 2=0$ \\
\hline & & \\
\hline & Boundary ab, bc, cd and da & Pore Pressure $P p=18 \mathrm{MPa}$ \\
\hline & Borehole & Displacement $U 1=U 2=0$ \\
\hline \multirow{2}{*}{ Initial conditions } & Whole model & Pore Pressure $P p=18 \mathrm{MPa}$ \\
\hline & Whole model & $\sigma_{H}=43 \mathrm{MPa}, \sigma_{H}=33 \mathrm{MPa}$ and $\sigma_{V}=35 \mathrm{MPa}$ \\
\hline
\end{tabular}

Table 1: The loads, boundary conditions and initial conditions in the investigation.

\section{Boundary conditions and basic simulation parameters}

The loads, boundary conditions and initial conditions adopted herein have been presented in Tab.1. As can be seen in Tab.1, The normal displacement of both the outer boundaries and the borehole should all be set to 0 throughout the simulation, and the pore pressure at the outer boundaries should also be fixed to the original reservoir pressure. Before the fracturing simulation, the initial in-situ stresses and reservoir pressure within the model need to be initialized. Furthermore, it should be emphasized that the two perforation tips are regarded as injection points of fracturing fluid. The fracturing fluid is injected into the perforation holes at a constant rate during the fracturing operation. 


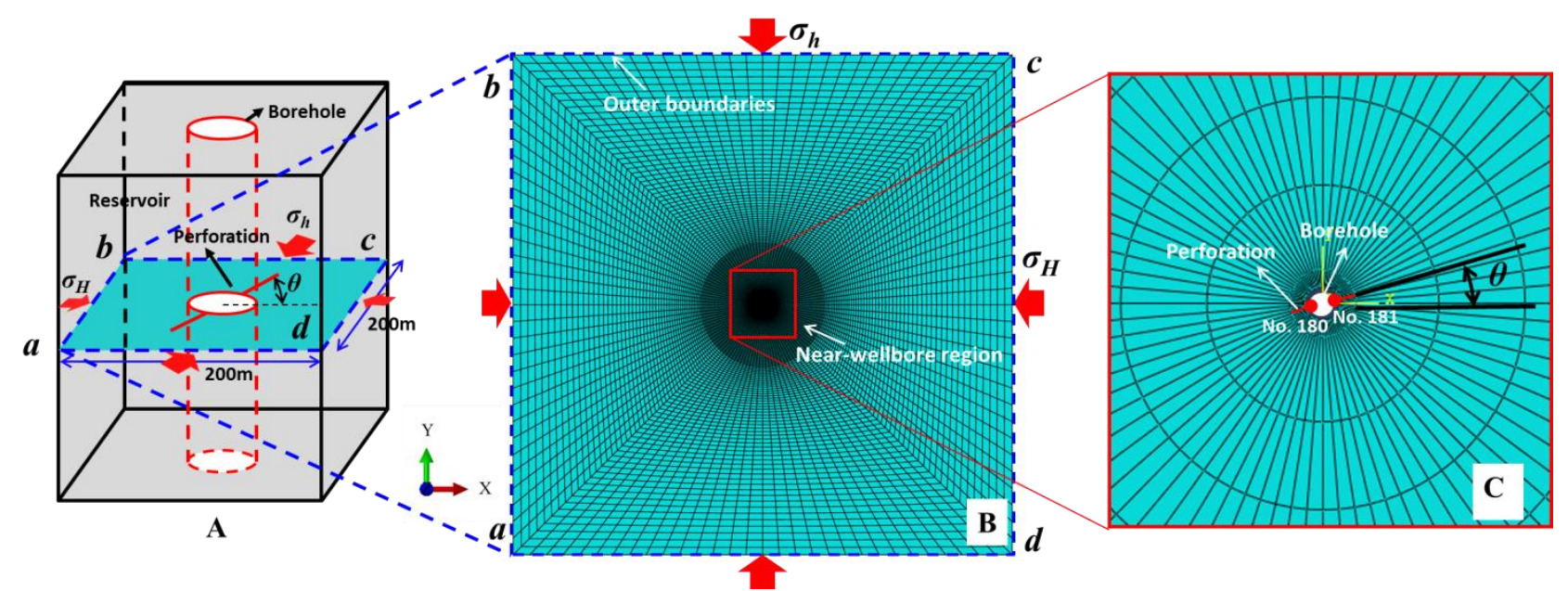

Figure 2: Schematic diagram of hydraulic fracturing with oriented perforation in shale reservoir and the established finite element model. (the perforation azimuth angle is $30^{\circ}$, and the perforation depth is $0.50 \mathrm{~m}$ ) (A): Formation model; (B): 2D finite element meshing model; (C): Meshing elements around borehole.

\begin{tabular}{cc|cc}
\hline Parameter & Value & Parameter & Value \\
Elastic Modulus E, GPa & 18 & Poisson's ratio $v$, Dimensionless & 0.25 \\
MPaximum horizontal principal stress $\sigma_{\mathrm{H}}$, & 43 & $\begin{array}{c}\text { Minimum horizontal principal stress } \sigma_{\mathrm{h},} \\
\text { MPa }\end{array}$ & 33 \\
Vertical principal stress $\sigma_{\mathrm{V}}, \mathrm{MPa}$ & 35 & Water saturation $S w, \%$ & 100 \\
Tensile strength $T s, \mathrm{MPa}$ & 3 & Initial porosity $\varphi, \%$ & 4 \\
Initial pore pressure $P_{p 0}, \mathrm{MPa}$ & 18 & Leak-off coefficient $C_{\text {leak-off }} \mathrm{m} /(\mathrm{MPa} \cdot \mathrm{s})$ & $1 \times 10^{-12}$ \\
Permeability $k, \mathrm{~m}^{2}$ & $5 \times 10^{-17}$ & Side length $L, \mathrm{~m}$ & 200 \\
Viscosity of fracturing fluid $\mu, \mathrm{mPa} \cdot \mathrm{s}$ & 30 & Injection rate $Q, \mathrm{~m}{ }^{3} / \mathrm{min}$ & 10 \\
Borehole radius $\mathrm{r}, \mathrm{m}$ & 0.20 & Perforation depth $P_{d, \mathrm{~m}}$ & 0.50 \\
Total fracturing time $T$, min & 10 & Reservoir depth $\mathrm{D}, \mathrm{m}$ & 2000 \\
Perforation azimuth $\theta,{ }^{\circ}$ & 40 & & \\
\hline
\end{tabular}

Table 2: Basic parameters for simulation.

Although Tab.1 has presented how loads, boundary conditions and initial conditions are applied, no specific values are given. For this purpose, Tab.2 gives the basic data required for simulation. Based on these data, the simulation can be conducted in this paper.

\section{Implementation of fracture initiation and reorientation in $A B A Q U S$}

Although most of the simulation involved in this paper can be done directly by CAE interface in ABAQUS software, secondary development is required for some settings. In this work, a text file with extension .inp is outputted after inputting basic parameters to the simulation software, and secondary development can be conducted by manually modifying this file. Fig.3 shows what needs to be modified in the *.inp file. As can be clearly seen in Fig.3, two contents need to be modified to achieve secondary development:

$>$ The fluid injection parameters need to be added into the *.inp file. The content (1) in Fig.3 means that the fracturing fluid is continuously injected at a rate of $5 \times 10^{-6} \mathrm{~m}^{3} / \mathrm{s}$ at two nodes numbered 180 and 181 within the instance named Part-1-1. 


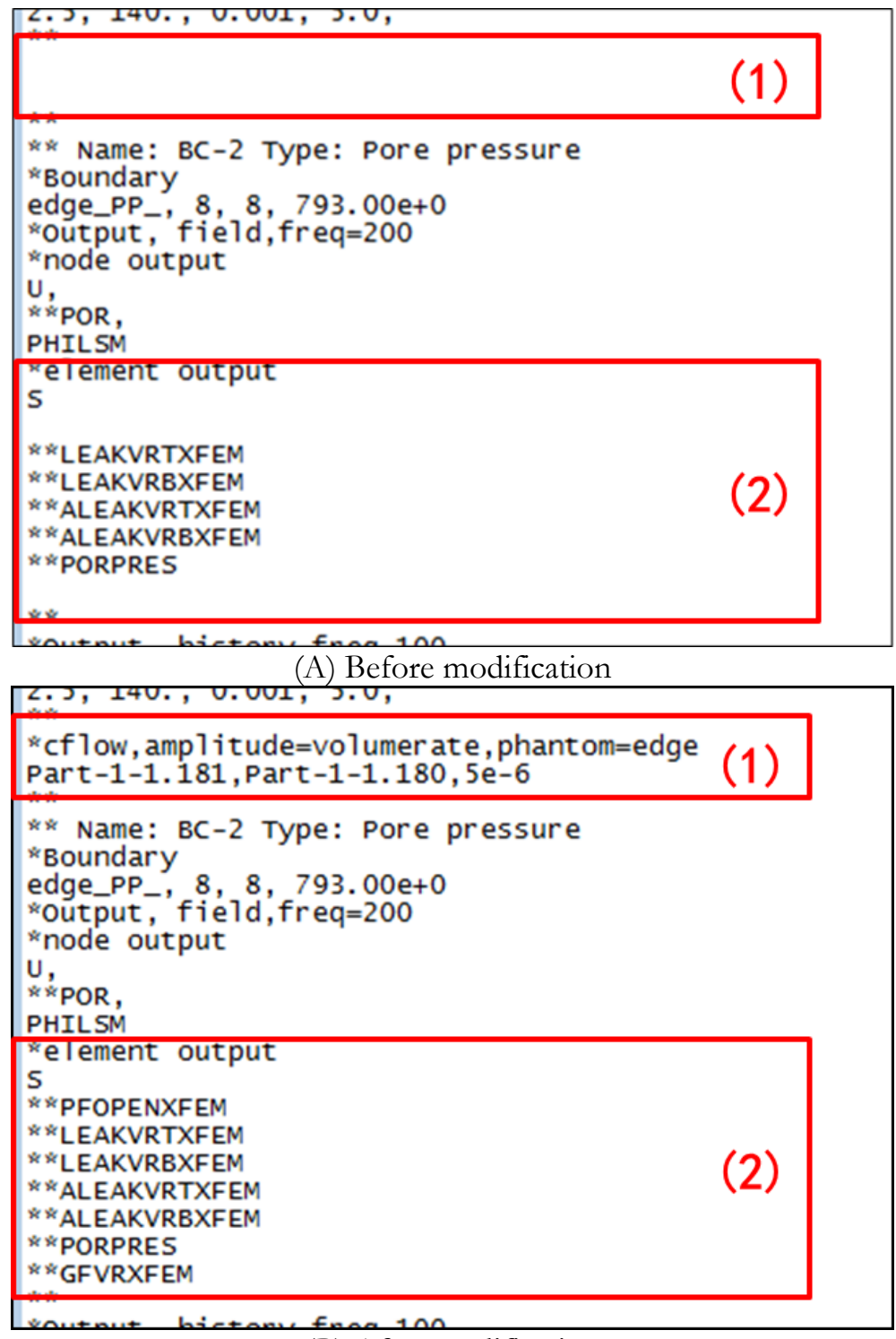

(B) After modification

Figure 3: Comparison of the *inp file before and after modification.

$>$ In addition, some simulation results need to be manually outputted. Contents (2) in Fig.3 are some output variables that need to be manually edited in file with extension .inp. Modification (2) in Fig.3 are

PFOPENXFEM: width of the hydraulically induced fracture;

LEAKVRTXFEM and LEAKVRBXFEM: Leak-off flow rate of two interfaces of fracture in 2D model;

ALEAKVRTXFEM and ALEAKVRBXFEM: Total leak-off flow volume from two interfaces of fracture within a 2D model;

PORPRES: Pore pressure of the element damaged by the hydraulically induced fracture.

The relevant results of hydraulically induced fracture are read from the result file in the form of *.odb when the simulation has been completed, thereby obtaining the initiation pressure and the reorientation radius. In addition, as can be seen in Tab.2, the injection rate is a constant value. However, in order to prevent the non-convergence caused by the sudden change of injection rate at the beginning of simulation, some measures need to be taken. As shown in Fig.4, the injection rate is gradually increased from 0 to the set value during the first 10 seconds. In this way, injection evolution of fracturing fluid at the beginning of fracturing operation becomes smoother, and the simulation process is more stable. Of course, the injection pattern displayed in Fig.4 needs to be realized by the amplitude function. 


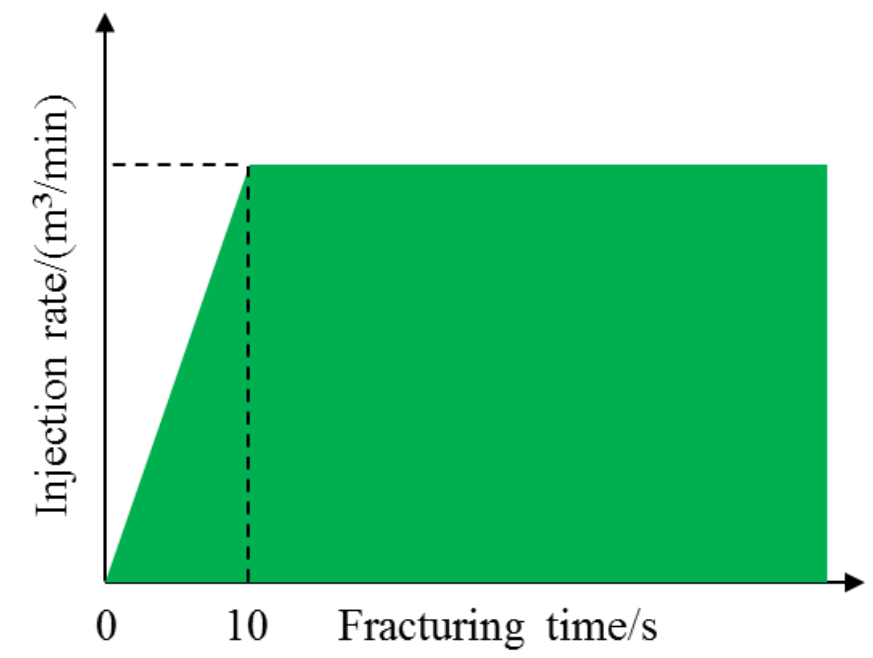

Figure 4: Evolution of injection rate during fracturing operation.

\section{Verification of the simulation model}

Model validation refers to exploring the applicability of the established model to investigations. The applicability of the investigation model used in this paper has been verified numerically and/or experimentally in several studies [14, 30]. In the present work, the applicability of the investigation model given in Fig.2 is verified by comparing the experiment in References [31] with the simulation in this paper. However, it should be noted that the simulation conditions (Of course, numerical scaling is required according to dimensional analysis.) should be all consistent with experimental conditions in reference [31]. The experimental conditions are summarized in Tab.3.

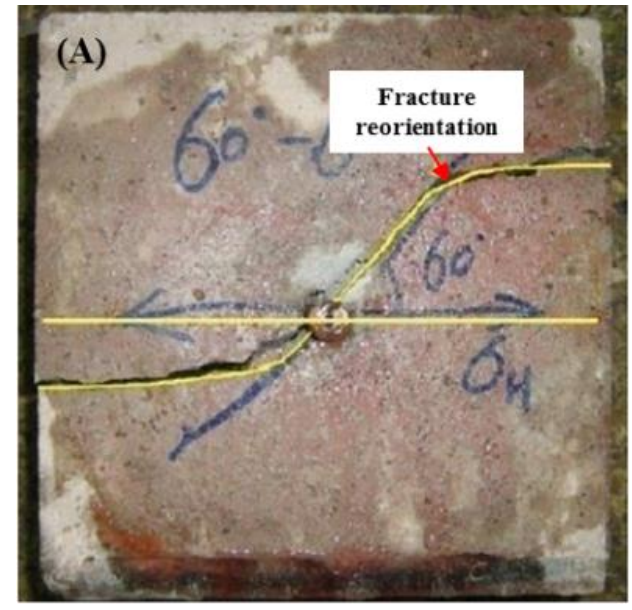

Reference [31]

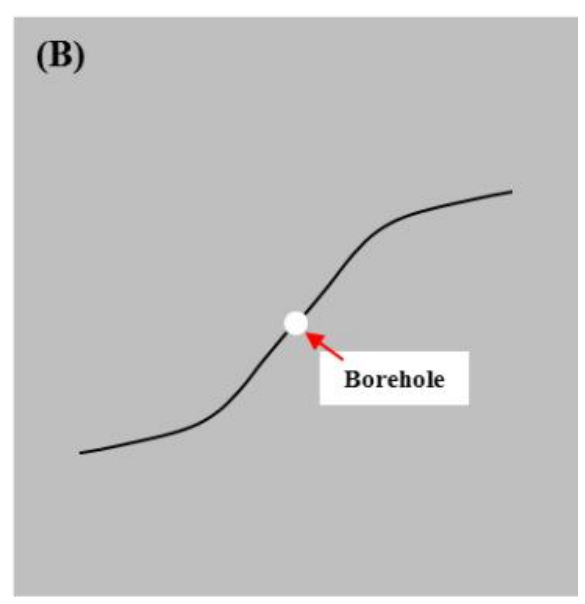

Simulation

Figure 5: Comparison of the experimental result in reference [31] with the simulation result.

Fig.5 illustrates the comparison of the experimental result with the simulation result. By Fig.5, we can clearly see that the fracture morphology obtained by experiment (see Fig.5A) and simulation (see Fig.5B) is similar, which can qualitatively verify the applicability of the investigation model. In order to quantitatively verify the applicability, Tab. 4 compares the experiment and the simulation by two parameters, i.e. initiation pressure and reorientation radius. By comparison, it can be found that the initiation pressure in simulation is only $0.29 \mathrm{MPa}$ lower than that in experiment, and the redirection radius in simulation is also only $0.18 \mathrm{~cm}$ shorter than that in experiment. All the above comparisons show that the investigation model in this paper can be used for analysis of both the initiation and the redirection of hydraulically induced fractures during fracturing operation. 


\begin{tabular}{ccc}
\hline Conditions & Value & Unit \\
Viscosity of fracturing fluid & 73 & $\mathrm{mPa} \cdot \mathrm{s}$ \\
Maximum horizontal principal stress & 6 & $\mathrm{MPa}$ \\
Minimum horizontal principal stress & 1 & $\mathrm{MPa}$ \\
Tensile strength & 2.59 & $\mathrm{MPa}$ \\
Porosity & 1.85 & $\%$ \\
Permeability & $1 \times 10^{-16}$ & $\mathrm{~m}^{2}$ \\
Elastic Modulus & 8.402 & $\mathrm{GPa}$ \\
Poisson's ratio & 0.23 & - \\
Injection rate & $2.1 \times 10^{-9}$ & $\mathrm{~m}^{3} / \mathrm{s}$ \\
Perforation depth & 0.05 & $\mathrm{~m}$ \\
Perforation azimuth & 60 & $\circ$ \\
\hline
\end{tabular}

Table 3: Experimental conditions in Reference [31].

\begin{tabular}{ccc}
\hline Parameter & Experiment in Reference [31] & Simulation \\
Initiation pressure, $\mathrm{MPa}$ & 15.55 & 15.26 \\
Redirection radius, $\mathrm{cm}$ & 8.30 & 8.48 \\
\hline
\end{tabular}

Table 4: Verification results of the simulation model.

\section{RESULTS AND DISCUSSIONS}

$\mathrm{I}$ $\mathrm{n}$ order to deeply understand both the initiation and the reorientation of hydraulically induced fractures during fracturing operation with oriented perforations, influences of different factors on them were investigated. Therefore, all data in Tab.2 are the benchmark data. When investigating the influence of certain factor on fracture reorientation, it is only necessary to adjust the corresponding data based on Tab.2. For example, if the effect of perforation azimuth on fracture reorientation was investigated, the perforation azimuth can be expanded from $40^{\circ}$ to five values of $0^{\circ}, 20^{\circ}, 40^{\circ}$, $60^{\circ}$ and $80^{\circ}$ based on Tab.2.

\section{Effect of perforation azimuth}

As mentioned above, hydraulically induced fractures will eventually propagate along the maximum horizontal principal stress during hydraulic fracturing. If the perforation does not follow the direction of the maximum horizontal principal stress, the fracture reorientation will occur, affecting the fracture morphology. Herein, fracture reorientation under five different perforation azimuths of $0^{\circ}, 20^{\circ}, 40^{\circ}, 60^{\circ}$, and $80^{\circ}$ was investigated. Fig. 6 shows the final fracture morphology with changing the perforation azimuth. It can be seen from Fig. 6 that regardless of the perforation azimuth, all fractures are initiated at the perforation tip after the fracturing operation has started for a period. Then, it propagates outward and gradually reorients to the $X$ direction (direction of the maximum principal stress), eventually forming a double-wing reoriented fracture. This indicates that perforation azimuth has little influence on the direction of fracture propagation, and the maximum principal stress is the main factor affecting the propagation direction. Moreover, with the increase of perforation azimuth, fracture reorientation becomes more obvious. Although the influence of perforation azimuth on fracture reorientation can be described intuitively and qualitatively from Fig.6, the quantitative conclusion can't be obtained. 


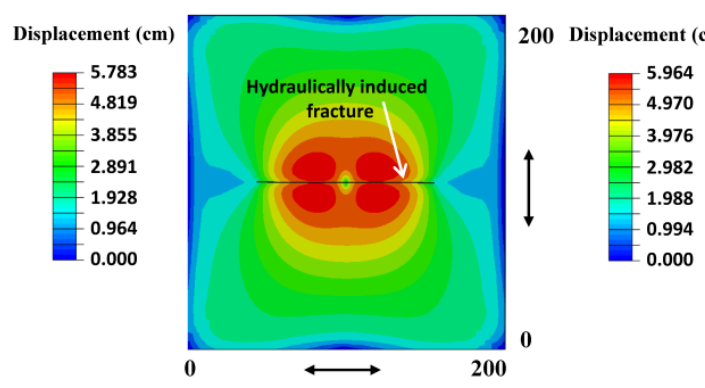

(A) Azimuth is 0 degree

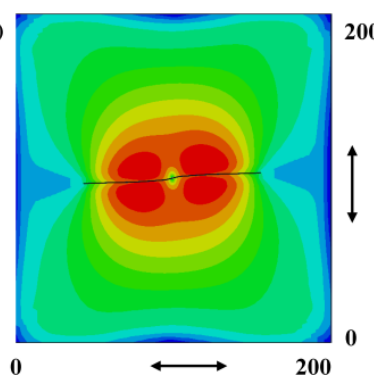

(B) Azimuth is 20 degree

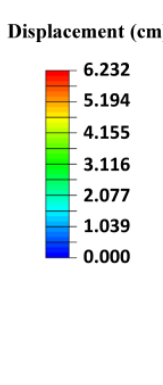

(C) Azimuth is 40 degree

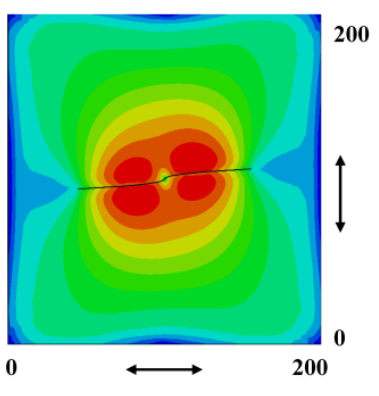

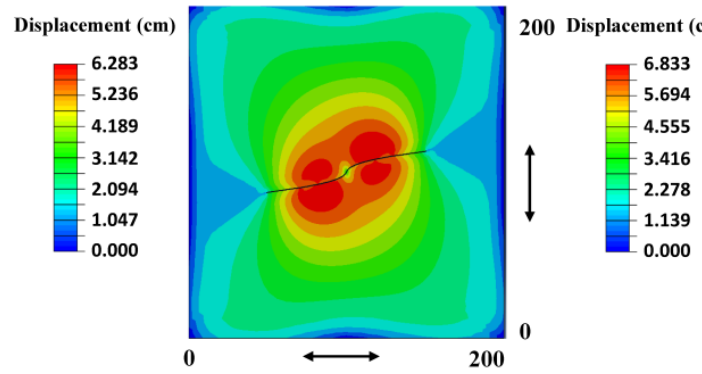

(D) Azimuth is 60 degree

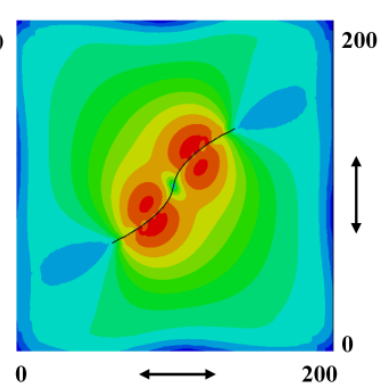

(E) Azimuth is 80 degree

Figure 6: The final fracture morphology when the perforation azimuth is different.

Therefore, Fig. 7 shows the effects of perforation azimuth on pressure evolution at injection node, fracture initiation and fracture reorientation during fracturing operation. Fracture initiation occurs when the pressure at injection node reaches a certain value, and the pressure at the injection node then gradually decreases from this time and eventually stabilizes [32]. The highest point of pressure evolution curve obtained in Fig.7A is usually defined as the initiation pressure [23]. Therefore, Fig.7B presented the relationship between the initiation pressure during fracturing and perforation azimuths. It can be clearly seen from Fig. $7 \mathrm{~B}$ that the initiation pressure increases with the increase of perforation azimuth. The initiation pressure is approximately $38.26 \mathrm{MPa}$ when the perforation coincides with the direction of the maximum horizontal principal stress. However, the initiation pressure reaches $52.57 \mathrm{MPa}$ when the perforation azimuth is $80^{\circ}$, which is $37.40 \%$ higher than that when the perforation azimuth is $0^{\circ}$. The main reason for this is that the bigger the perforation azimuth is, and the more energy is needed to overcome the shear stress to promote the fracture initiation.

If fracture reorientation is described by the parameter of redirection radius, the large reorientation radius of hydraulically induced fracture indicates the severe fracture reorientation. We can see from Fig.7C that the redirection radius increases non-linearly with the increase of perforation azimuth, and the perforation azimuth of about $62.5^{\circ}$ is the inflection point in Fig. 7 C. The increase rate of fracture reorientation radius is $0.42 \mathrm{~m} /{ }^{\circ}$ when the perforation azimuth is less than $62.5^{\circ}$, but it reaches $1.60 \mathrm{~m} /{ }^{\circ}$ when the perforation azimuth exceeds $62.5^{\circ}$. This is because that the area where stress changes during fracturing increases with the increase of perforation azimuth angle, so the hydraulically induced fracture propagates for longer path through this area.

Therefore, based on the numerical simulation in this section, we can draw the conclusion that perforation azimuth is preferably designed in the range of $0^{\circ}$ to $40^{\circ}$ during fracturing operation. This is because if the perforations are designed within this range, both the initiation pressure and the fracture pressure are relatively low, so that the operation efficiency can be effectively improved and the operation cost can be reduced.

\section{Effect of injection rate of fracturing fluid}

The injection rate is also an important factor affecting both the fracture reorientation and the final fracture morphology. In this section, seven injection rates, $4 \mathrm{~m}^{3} / \mathrm{min}, 6 \mathrm{~m}^{3} / \mathrm{min}, 8 \mathrm{~m}^{3} / \mathrm{min}, 10 \mathrm{~m}^{3} / \mathrm{min}, 12 \mathrm{~m}^{3} / \mathrm{min}, 14 \mathrm{~m}^{3} / \mathrm{min}$ and $16 \mathrm{~m}^{3} / \mathrm{min}$, are set to explore the influence of injection rate on fracture initiation and fracture reorientation. Moreover, the perforation azimuth adopted in these simulations is $40^{\circ}$. Fig. 8 shows the final fracture morphology when the injection rate is different. From Fig.8, we can qualitatively see that the injection rate of fracturing fluid has little effect on the reorientation of fractures during fracturing operation, but it will affect the propagation of fractures. In Fig.8A, when the injection rate is $4 \mathrm{~m}^{3} / \mathrm{min}$, the half-length of fracture is only about $50 \mathrm{~m}$. However, it reaches about $90 \mathrm{~m}$ when the injection rate has been 
increased to $16 \mathrm{~m}^{3} / \mathrm{min}$, which is nearly twice as long as the fracture length when the injection rate is $4 \mathrm{~m}^{3} / \mathrm{min}$ (see Fig. $8 \mathrm{G})$. As what we can see from Fig.8G, the numerical model in this paper is almost fractured into the upper and lower parts at the end of fracturing operation when the whole operation is carried out at a larger injection rate.

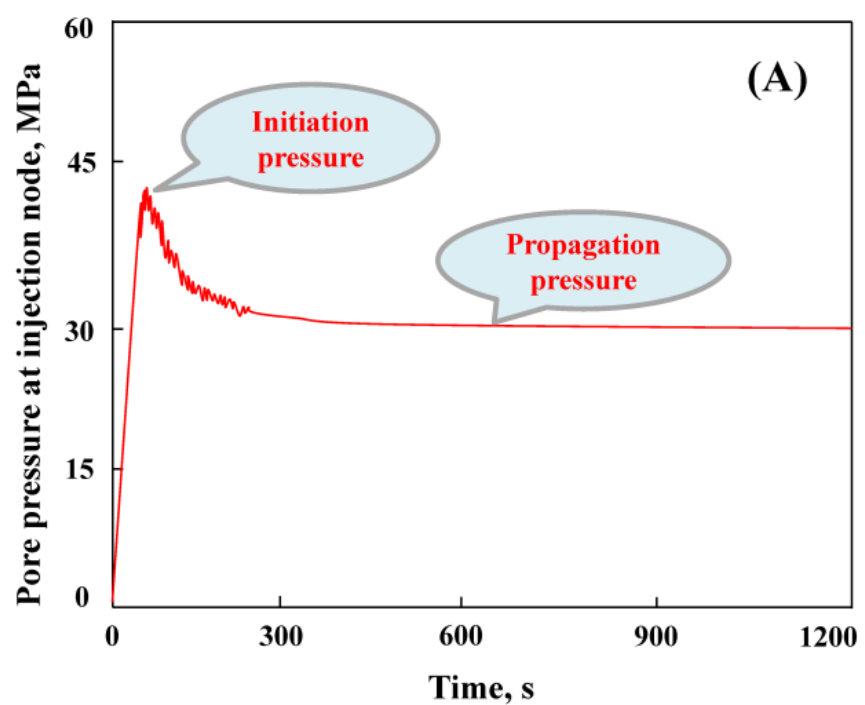

(A): Pressure evolution at the injection node during fracturing when the perforation azimuth is $40^{\circ}$

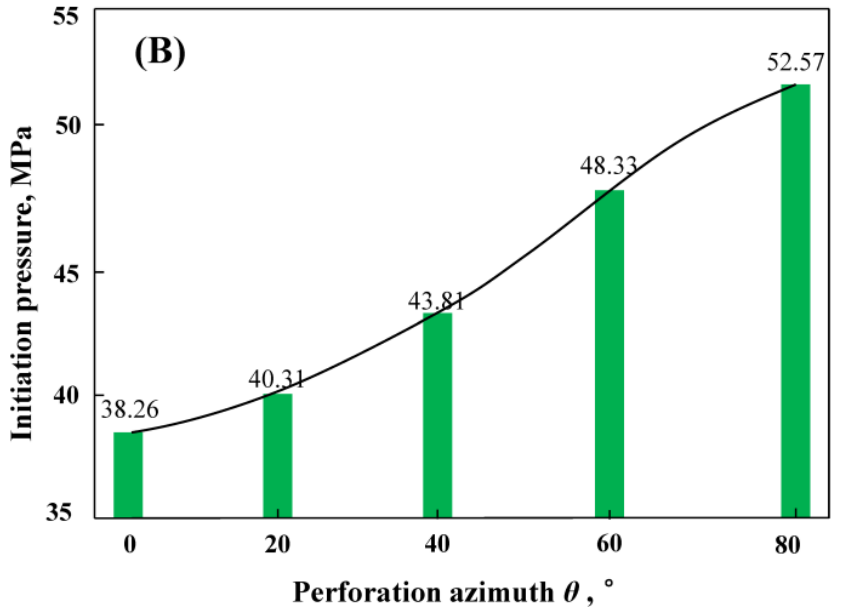

(B): Effects of perforation azimuth on fracture initiation

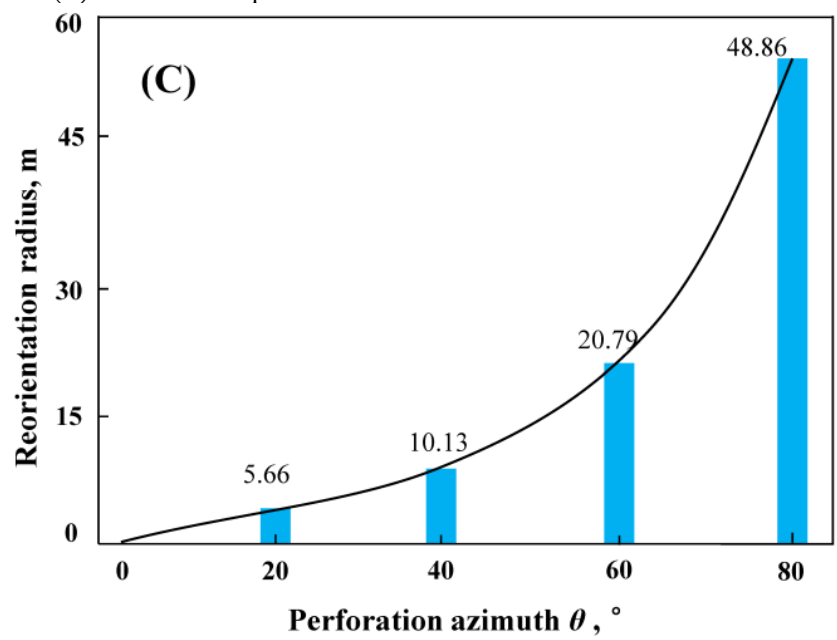

(C): Effects of perforation azimuth on and fracture reorientation

Figure 7: Effects of perforation azimuth on initiation pressure and fracture reorientation. 


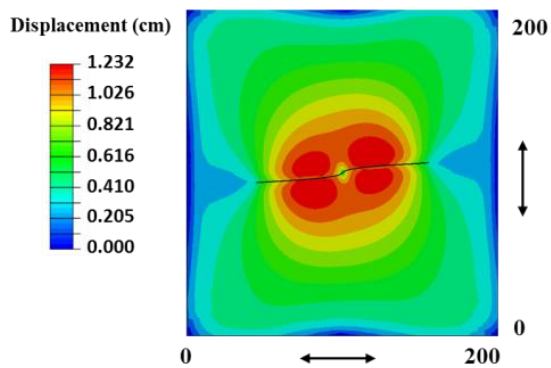

(A) $4 \mathrm{~m}^{3} / \mathrm{min}$

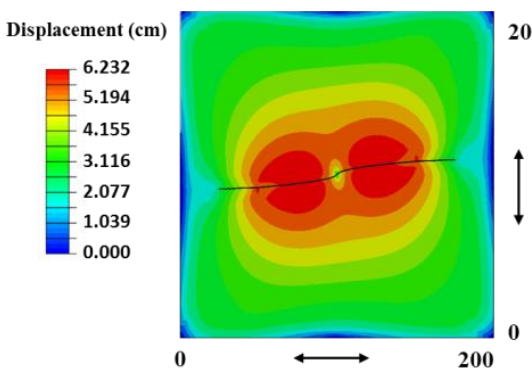

(D) $10 \mathrm{~m}^{3} / \mathrm{min}$

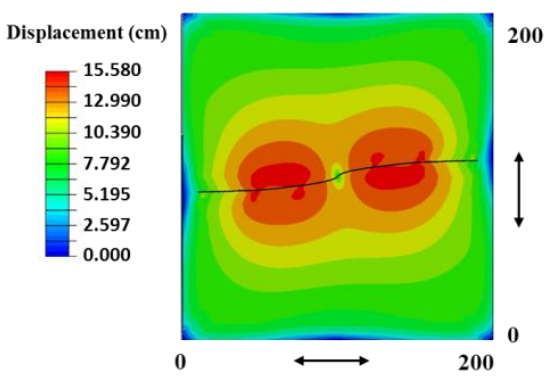

(G) $16 \mathrm{~m}^{3} / \mathrm{min}$
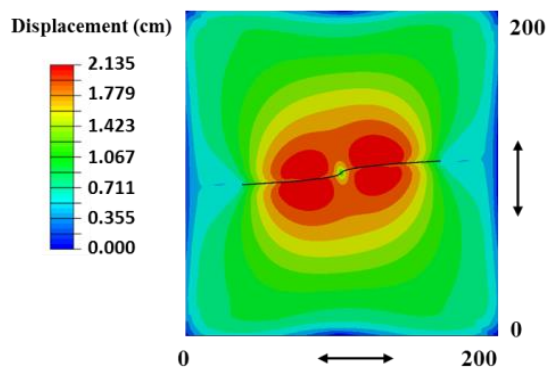

(B) $6 \mathrm{~m}^{3} / \mathrm{min}$
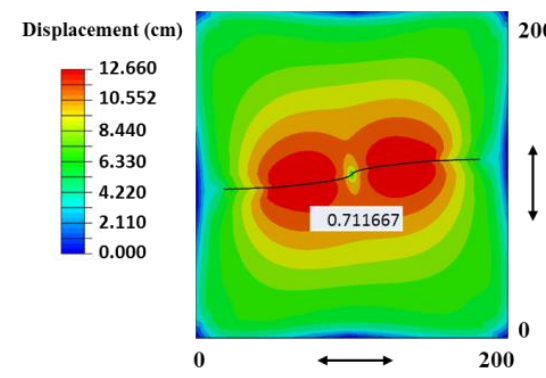

(E) $12 \mathrm{~m}^{3} / \mathrm{min}$

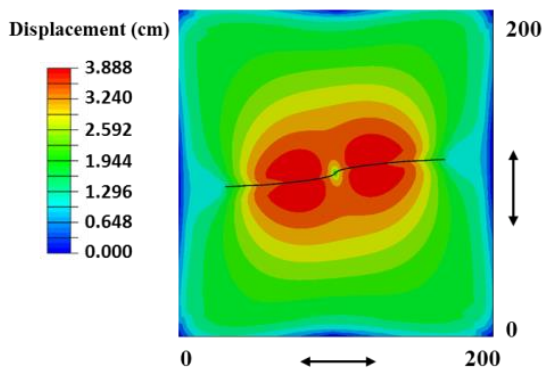

(C) $8 \mathrm{~m}^{3} / \mathrm{min}$
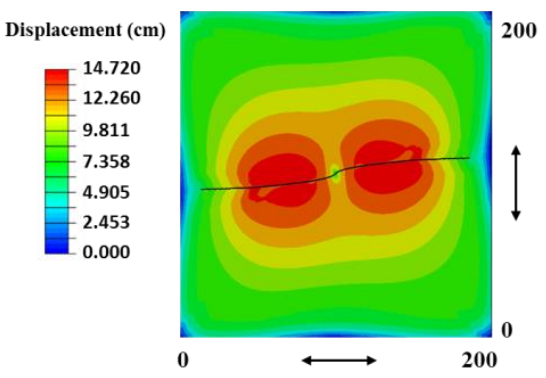

(F) $14 \mathrm{~m}^{3} / \mathrm{min}$

Figure 8: The final fracture morphology when the injection rate of fracturing fluid is different.

To quantitatively clarify the effects of injection rate on both fracture initiation and fracture reorientation, Fig.9 gives the initiation pressure and the reorientation radius when the fracturing fluid was injected at different injection rates during fracturing. We can see from Fig.9A that a larger injection rate results in the higher initiation pressure. The initiation pressure has increased from $37.26 \mathrm{MPa}$ to $53.03 \mathrm{MPa}$ when the injection rate was increased from $4 \mathrm{~m}^{3} / \mathrm{min}$ to $16 \mathrm{~m}^{3} / \mathrm{min}$. As expected, the simulation results show that fracture initiation occurs much earlier at a larger injection rate than that at a smaller one. This is because, for large injection rate, leak-off of fracturing fluid from perforation to reservoir can be almost completely neglected, less time is needed to increase the pressure of injection point to the initiation pressure.

Fig.9B displays the relationship between reorientation radius and injection rate. Although the effect of injection rate on fracture reorientation is not as pronounced as that of perforation azimuth, it can be seen from Fig.9B that the increasing injection rate of fracturing fluid can also worsen the fracture reorientation. The reorientation radius is only $13.05 \mathrm{~m}$ when the injection rate is designed as $16 \mathrm{~m}^{3} / \mathrm{min}$. Although large injection rate can effectively accelerate the fracturing operation and lengthen the fracture length, too large injection rate will increase the cost of fracturing operation. Of course, too small injection rate is still inappropriate for fracturing in shale reservoir. Therefore, the injection rate of 8 to $12 \mathrm{~m}^{3} / \mathrm{min}$ under the simulation conditions in this paper is more appropriate.

\section{Effect of difference between two horizontal principal stresses}

In this part, on the premise of keeping other basic parameters unchanged, the effect of difference between two horizontal principal stresses on fracture reorientation has been investigated by changing the minimum horizontal principal stress. The minimum horizontal principal stress is sequentially set to $33 \mathrm{MPa}, 35 \mathrm{MPa}, 37 \mathrm{MPa}, 39 \mathrm{MPa}, 41 \mathrm{MPa}$, and $43 \mathrm{MPa}$ in the form of an arithmetic progression. The maximum horizontal principal stress is a fixed value in the whole fracturing 
simulation. In other words, the difference between the two horizontal principal stresses is an arithmetic sequence with a tolerance of $2 \mathrm{MPa}$ between $0 \mathrm{MPa}$ and $10 \mathrm{MPa}$.

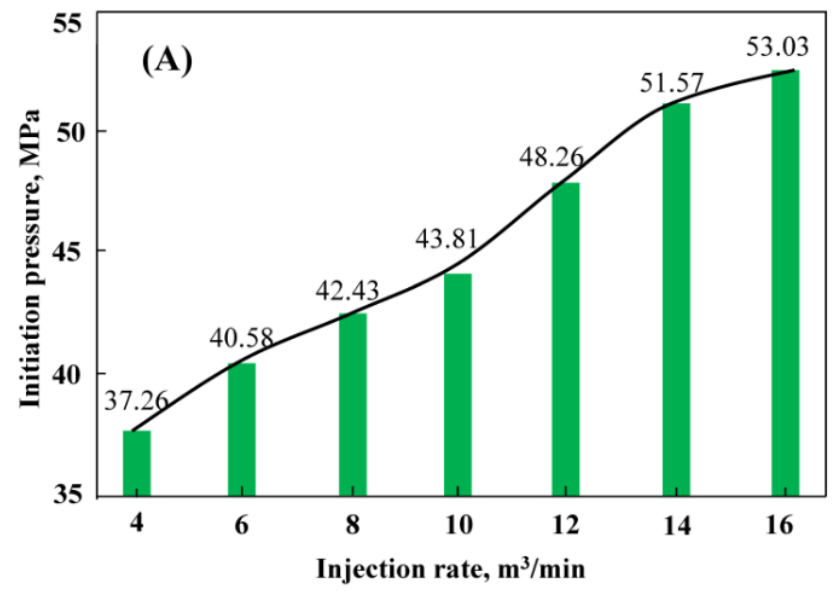

(A): Effect of injection rate on fracture initiation

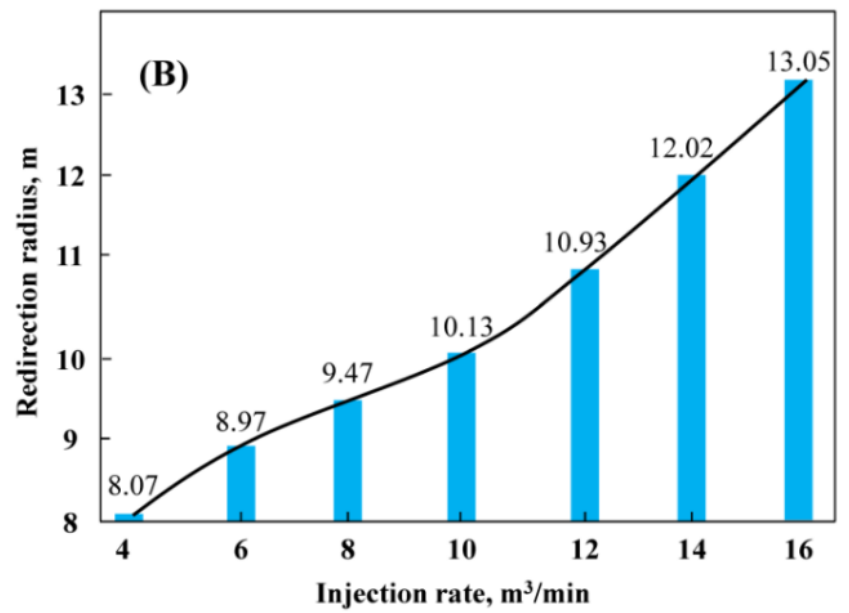

(B): Effect of injection rate on fracture reorientation

Figure 9: Effect of injection rate on initiation pressure and redirection radius during fracturing operation with oriented perforations in shale reservoirs.

The final fracture morphology when the difference between two horizontal principal stresses is different is shown in Fig.10. We can qualitatively see from Fig.10A that the hydraulically induced fracture is almost a straight-line propagating along the perforations during fracturing operation when the two horizontal principal stresses are equal to each other. On the contrary, fracture reorientation occurs more pronouncedly when the difference between two horizontal principal stresses is greater (see Fig.10B to Fig.10F). Although it can be clearly seen from Fig.10 that the difference between two horizontal principal stresses will significantly affect fracture reorientation, the quantitative description is necessary. Therefore, Fig.11 quantitatively describes the influence of stress difference on initiation pressure (see Fig.11A) and reorientation angle (see Fig.11B) during fracturing operation. We can see from Fig.11A that when the minimum horizontal principal stress is $43 \mathrm{MPa}$ (i.e., stress difference is $0 \mathrm{MPa}$ ), the initiation pressure is $52.24 \mathrm{MPa}$. Moreover, with the increase of difference between the two horizontal principal stresses, initiation of hydraulically induced fracture becomes easier and easier. The initiation pressure decreases to $43.81 \mathrm{MPa}$ when the minimum horizontal principal stress is $33 \mathrm{MPa}$ (i.e., stress difference is $10 \mathrm{MPa}$ ). This is due to the strong stress concentration at the tip of the perforation when the difference between two horizontal principal stresses is significant, which is conducive to the initiation of hydraulically induced fracture. 


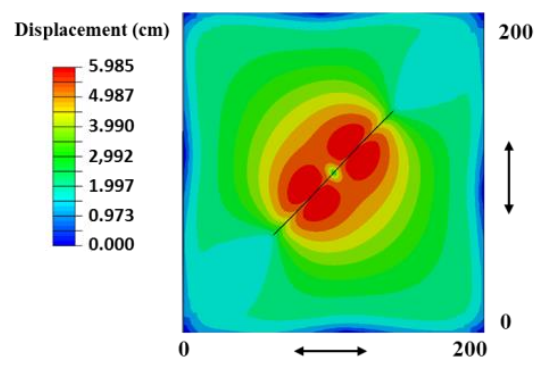

(A) $\sigma_{H}=\sigma_{h}=43 \mathrm{MPa}$

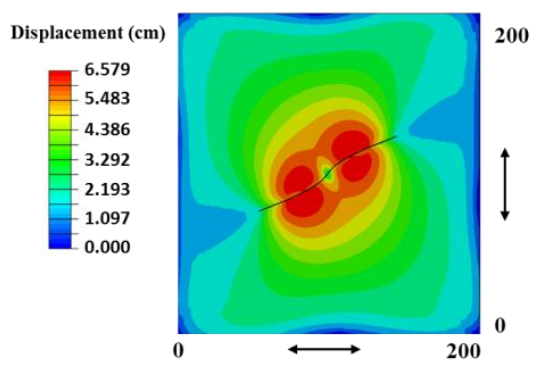

(D) $\sigma_{H}=43 \mathrm{MPa}, \sigma_{h}=37 \mathrm{MPa}$

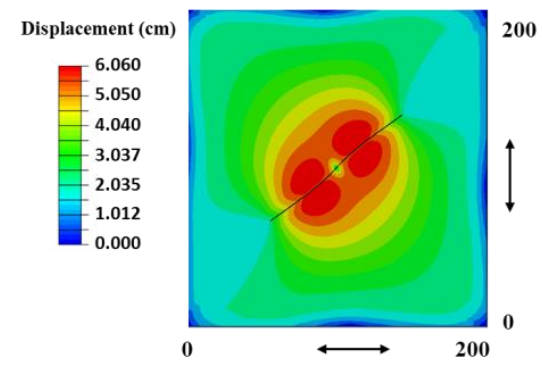

(B) $\sigma_{H}=43 \mathrm{MPa}, \sigma_{h}=41 \mathrm{MPa}$

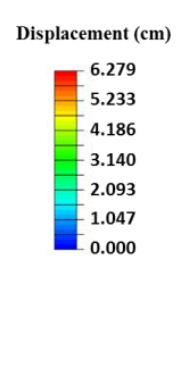

(C) $\sigma_{H}=43 \mathrm{MPa}, \sigma_{h}=39 \mathrm{MPa}$

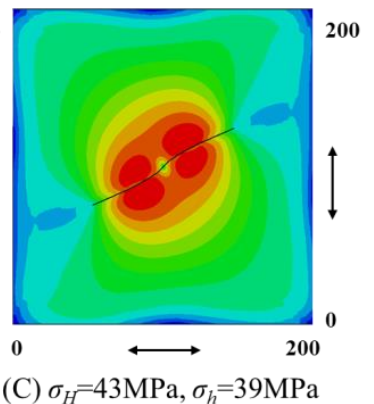

200

\section{(1)}

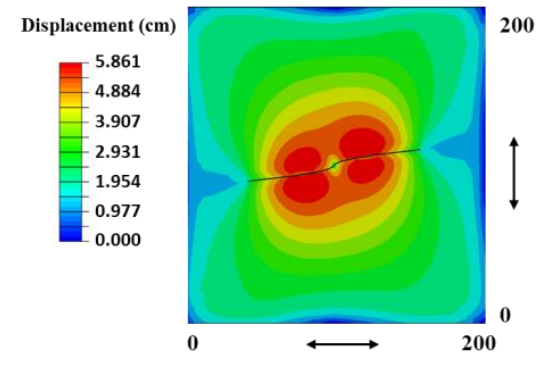

(E) $\sigma_{H}=43 \mathrm{MPa}, \sigma_{h}=35 \mathrm{MPa}$

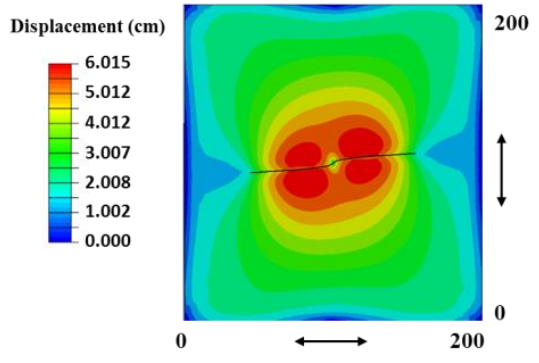

(F) $\sigma_{H}=43 \mathrm{MPa}, \sigma_{h}=33 \mathrm{MPa}$

Figure 10: The final fracture morphology when the difference between two horizontal principle stresses is different.

As can be seen in Fig.11B, the reorientation of hydraulically induced fracture will be aggravated with the increase of difference between the two horizontal principal stresses. As described in Fig.10A, no fracture reorientation occurs (i.e., reorientation angle is $0^{\circ}$ ) when the difference between two horizontal principal stresses is 0MPa. However, the reorientation angle is $41.73^{\circ}$ when the minimum horizontal principal stress is $33.00 \mathrm{MPa}$ (i.e., stress difference is $10 \mathrm{MPa}$ ). From this, we can know that the difference between two horizontal principal stresses is the most important factor that determines whether the fracture reorientation can occur during fracturing operation. Although in-situ stresses are not a human intervention factor, the simulation results can be used to properly guide the design of fracturing operations.

\section{Effect of fluid viscosity}

The viscosity of hydraulic fluid can also affect the initiation and reorientation of fractures during fracturing operation. Based on the parameters listed in Tab.2, the initiation pressure and reorientation radius are investigated respectively when the fluid viscosity is $30 \mathrm{mPa} \cdot \mathrm{s}, 60 \mathrm{mPa} \cdot \mathrm{s}, 90 \mathrm{mPa} \cdot \mathrm{s}, 120 \mathrm{mPa} \cdot \mathrm{s}, 150 \mathrm{mPa} \cdot \mathrm{s}$ and $180 \mathrm{mPa} \cdot \mathrm{s}$.

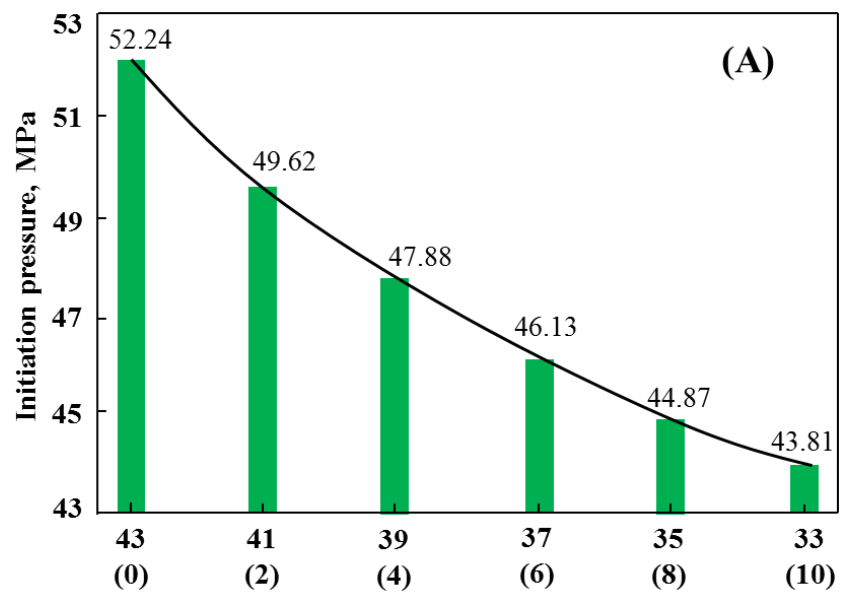

Minimum horizontal stress, MPa

(Stress difference, MPa) 


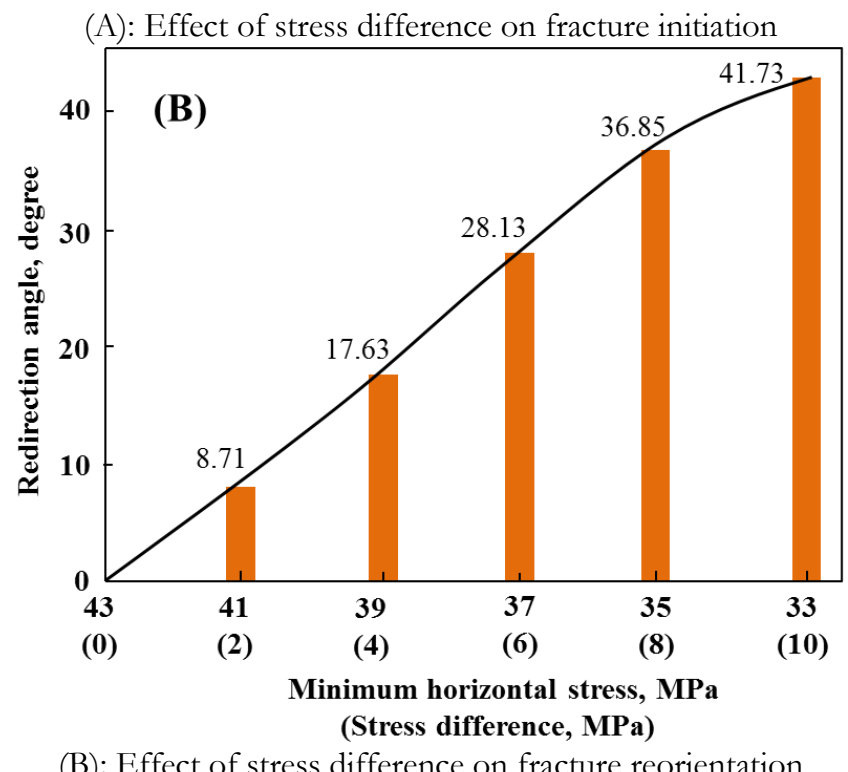

Figure 11: Effect of difference between two horizontal principal stresses on initiation pressure and reorientation radius during fracturing.

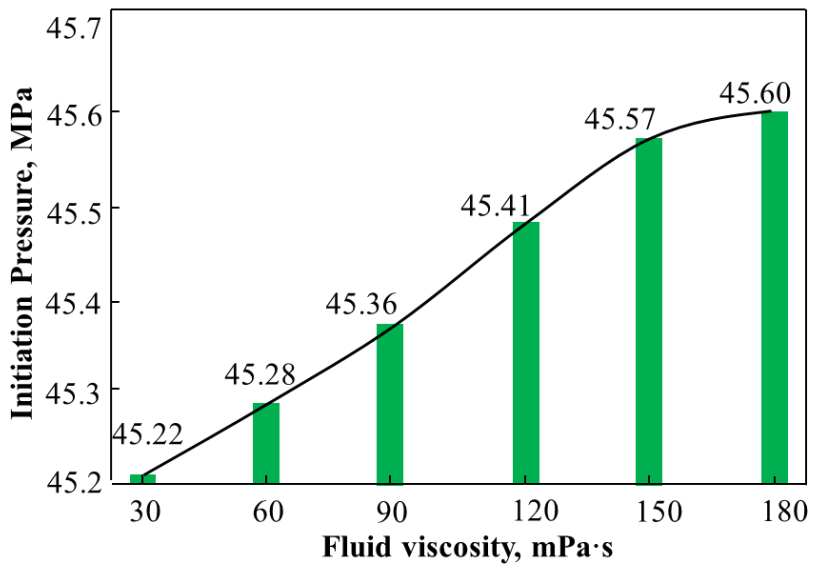

Figure 12: Effect of fluid viscosity on fracture initiation during fracturing operation with oriented perforations in shale reservoirs.

Fig.12 exhibits the influence of fluid viscosity on initiation pressure during fracturing with oriented perforations when fluid viscosity is different. From Fig.12, we can see that the initiation pressure will increase with the increase of fluid viscosity, but the fluid viscosity has little effect on the fracture initiation pressure. The initiation pressure has increased from $45.22 \mathrm{MPa}$ to $45.60 \mathrm{MPa}$ when the fluid viscosity changes from $30 \mathrm{mPa} \cdot \mathrm{s}$ to $180 \mathrm{mPa} \cdot \mathrm{s}$, with an increase of $0.38 \mathrm{MPa}$. With the help of Fig.13, the mechanism of the effect of fluid viscosity on the initiation pressure for fracturing operation can be well explained. From Fig.13A, we can see that when the fluid viscosity is low, the fracturing fluid in perforation will more easily invade into shale reservoir, and the seepage resistance of fracturing fluid with lower viscosity in shale reservoir is also smaller. When the fluid viscosity is $30 \mathrm{mPa} \cdot \mathrm{s}$, the invasion distance is $12.52 \mathrm{~cm}$ around perforation. It is not so easy to maintain the pressure in perforation at the beginning of fracturing operation, a large amount of fracturing fluid will invade into reservoir before fracture initiation occurs at the perforation tip. In this case, the initiation pressure will be small when the fracturing fluid viscosity is low. On the contrary, as shown in Fig.13B, when the fluid viscosity is high, it is difficult for fracturing fluid to invade into reservoir, and pressure holding in perforation is easy to achieve [33]. When the fluid viscosity is $30 \mathrm{mPa} \cdot \mathrm{s}$, the invasion distance is $4.63 \mathrm{~cm}$ around perforation. Therefore, when the fluid viscosity is high, fracture initiation has already begun to occur before the fracturing fluid in perforation invades into the reservoir violently, and the initiation pressure is high. 


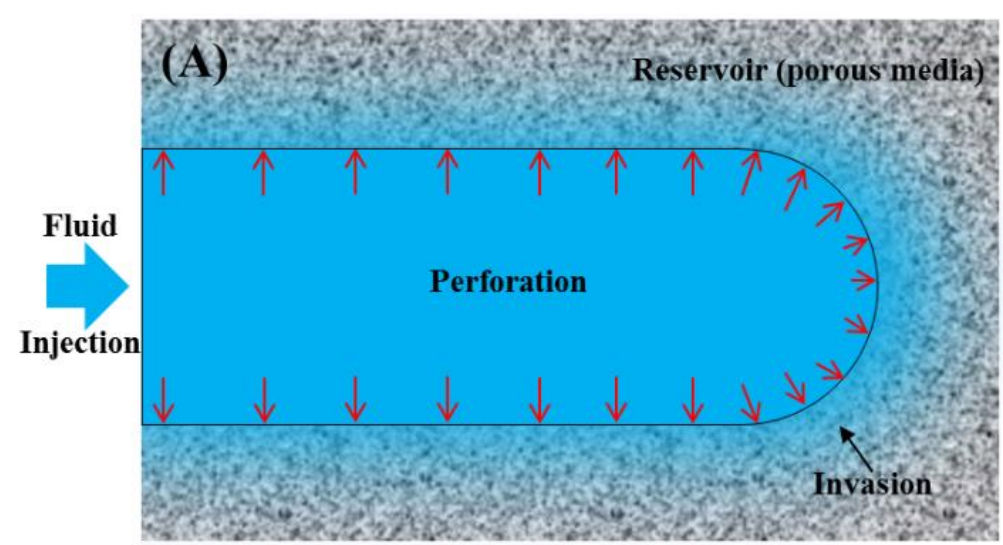

(A): Low fluid viscosity

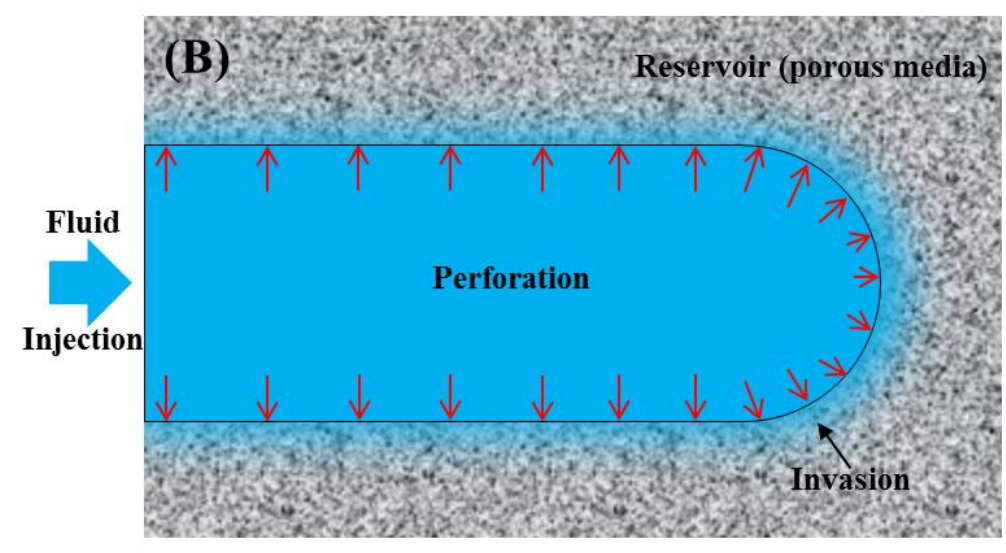

(B): High fluid viscosity

Figure 13: Fluid invasion from perforation to reservoir during fracturing operation with oriented perforations in shale reservoirs.

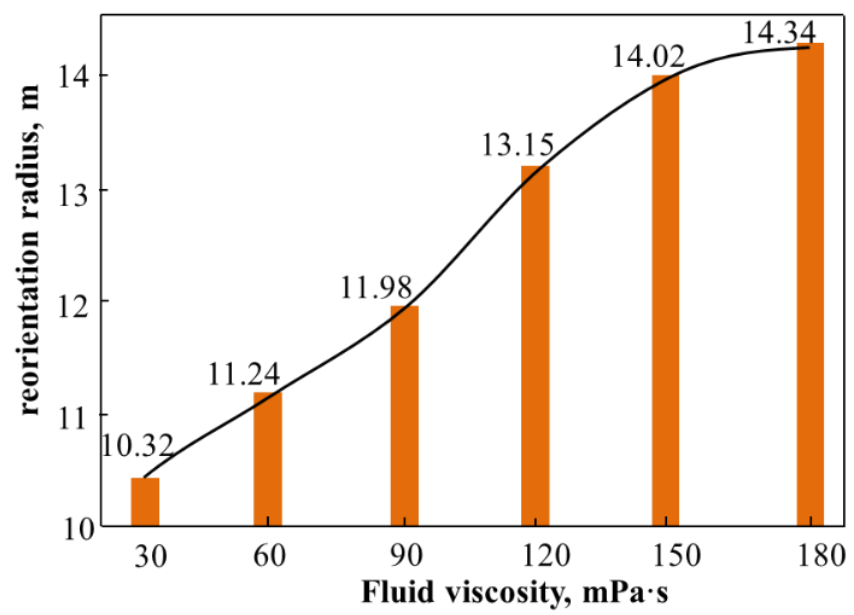

Figure 14: Effect of fluid viscosity on reorientation radius during fracturing operation with oriented perforations in shale reservoirs.

Fig.14 displays the influence of fluid viscosity on reorientation radius of hydraulically induced fracture during fracturing operation with oriented perforations in shale reservoirs. We can see from Fig.14 that the reorientation radius of hydraulically induced fracture will nonlinearly become longer with the increase of fluid viscosity. When the fluid viscosity is $30 \mathrm{mPa} \cdot \mathrm{s}$, the reorientation radius is only $10.32 \mathrm{~m}$. However, the reorientation radius has increased to $14.34 \mathrm{~m}$ when the fluid viscosity is $180 \mathrm{mPa} \cdot \mathrm{s}$, which is $4.02 \mathrm{~m}$ longer than that when the fluid viscosity is $30 \mathrm{mPa} \cdot \mathrm{s}$. This can also be explained by Fig.13. As shown in Fig.13, when the fluid viscosity is high, fluid within the perforation is difficult to invade into the reservoir, and the pressure in perforation is high. Therefore, when the fluid viscosity is high, the fracture has propagated a long distance before reorientation. 


\section{CONCLUSIONS AND FUTURE WORK}

I

$\mathrm{n}$ the present work paper, factors (such as the injection rate and the in-situ stresses) affecting fracture initiation and fracture reorientation have been numerically investigated by the XFEM-Based Cohesive Zone Method with ABAQUS software. The main conclusions are summarized as follows:

(1) Model verification is necessary and important for the numerical simulation. In the present work, model verification was conducted by comparing the experiment in public article and the simulation herein. Through comparison, it is found that the simulation results are almost consistent with the experimental results, which shows that the simulation model herein is suitable for all investigations in the present work.

(2) Perforation around wellbore facilitates fracture initiation during fracturing operation, and the fracture typically initiates at the perforation tip. Although the perforation azimuth has little influence on the direction of fracture propagation, it severely affects fracture initiation and fracture reorientation. Investigation on the effects of perforation azimuth on fracture initiation and reorientation shows that both the initiation pressure and the reorientation radius increase sharply with the increase of perforation azimuth. Although larger perforation azimuth is beneficial to the formation of complex fractures, it cannot be designed to be very large. Considering the cost and effectiveness of the operation, the perforation azimuth is recommended to be in the range of $0^{\circ}$ to $40^{\circ}$.

(3) As we all know, the driving force for initiation and propagation of hydraulic fractures in fracturing operation mainly comes from the fluid injection into the perforations. Therefore, injection rate of fracturing fluid is also an important factor affecting the fracture morphology. Investigation results show that increasing the injection rate of fracturing fluid can not only increase the initiation pressure during fracturing operation, but also make the fracture reorientation more difficult.

(4) As the difference between the two horizontal principal stresses increases, the shear stress at the tip of the perforation easily reaches the tensile strength and fracture occurs. If the initial pressure is used to reflect the influence of the stress difference on the initiation of the fracture, the initial pressure will decrease as the stress difference increases. Moreover, the reorientation radius becomes longer as the stress difference increases. Although the in-situ stress is not a factor we can control, the investigation can provide reference for engineering design by adjusting some other factors (such as injection rate and perforation azimuth).

(5) Fluid viscosity affects the initiation and reorientation of fractures by affecting the invasion of fracturing fluid from perforation into reservoir during fracturing. The investigation results show that both the initiation pressure and the reorientation radius increase with the increase of fluid viscosity.

All the investigations herein are aimed at factors affecting the initiation and reorientation of the single fracture, but the interaction between fractures will affect the fracture morphology. Therefore, in the following investigation, we will focus on the interaction between fractures during fracturing.

\section{ACKNOWLEDGEMENTS}

his work is supported by the Postdoctoral Program of Henan Polytechnic University (Grant No. 712108/210) and the National Key Research and Development Program (Grant No. 2016YFC0304005).

\section{REFERENCES}

[1] Zou, C., Zhao, Q., Dong, D., Zhao, Q., Dong, D., Yang, Z., Qiu, Z., Liang, F., Wang, N., and Huang, Y. (2017). Geological characteristics, main challenges and future prospect of shale gas, Journal of Natural Gas Geoscience, 2(56), pp. 273-288. DOI: 10.1016/j.jnggs.2017.11.002.

[2] Technically Recoverable Shale Oil and Shale Gas Resources: An Assessment of 137 Shale Formations in 41 Countries Outside the United States. https://www.eia.gov/analysis/studies/worldshalegas/pdf/overview.pdf (2013).

[3] IEA. World Energy Outlook 2017. https://iea.blob.core.windows.net/assets/4a50d774-5e8c-457e-bcc9-513357f9b2f b/World_Energy_Outlook_2017.pdf (2017).

[4] Miguel, M. (2015). Hydraulic Fracturing: An overview and a Geomechanical approach, Master thesis, Lisbon University. 
[5] Vengosh, A., Jackson, R. B. and Warner, N. (2014). A critical review of the risks to water resources from unconventional shale gas development and hydraulic fracturing in the united states, Environmental Science \& Technology, 48(15), pp. 8334-8348. DOI: 10.1021/es405118y.

[6] Kumar, D., Gutierrez, M., Frash, L. P., and Hampton, J. (2015). Numerical Modeling of Experimental Hydraulic Fracture Initiation and Propagation in Enhanced Geothermal Systems. 49th U.S. Rock Mechanics/Geomechanics Symposium, American Rock Mechanics Association, ARMA 15-253.

[7] Biao, F., Liu, H., Zhang, J., Zhang, S., and Wang, X. (2011). A numerical study of fracture initiation pressure under helical perforation conditions, Journal of University of Science \& Technology of China, 41(3), pp. 219-226. (In Chinese) DOI: 10.3969/j.issn.0253-2778.2011.03.006.

[8] Zhang, G., Chen, M., Yin, Y., and Sun, H. (2003). Study on influence of perforation on formation fracturing pressure, Chinese Journal of Rock Mechanics and Engineering, 22(1), pp. 40-44. (In Chinese)

[9] Zhu, H., Deng, J., Liu, S., and Peng, C. (2013). A prediction model for the hydraulic fracture initiation pressure in oriented perforation, Acta Petrolei Sinica, 34(3), pp. 556-562. DOI: 10.7623/syxb201303021.

[10] Wright, C., and Leen, W. (2001). Hydraulic fracture reorientation: Does it occur? Does it matter?, The Leading Edge, 20(10), pp. 1185-1189. DOI: 10.1190/1.1487252.

[11] Li, Q., Cheng, Y., Zhou, D., Li, Q., and Ansari, U. (2018). Effect of inter-cluster interference on the fracture morphology in multi-cluster staged fracturing for shale reservoir, Frattura ed Integrità Strutturale, 12(44), pp. 35-48. DOI: $10.3221 /$ IGF-ESIS.44.04.

[12] Chang, X., Wang, H., Cheng, Y., and Han, X. (2015). Experimental Study of Fracture Propagation Mechanisms by Oriented Perforation Technology for SRV Fracturing, Advances in Petroleum Exploration and Development, 10(2), pp. 44-49. DOI: 10.3968/7621.

[13] Zhu, H., Deng, J., Jin, X., Hu, L., and Bo, L. (2015). Hydraulic fracture initiation and propagation from wellbore with oriented perforation, Rock Mechanics \& Rock Engineering, 48(2), pp. 585-601. DOI: 10.1007/s00603-014-0608-7.

[14] Li, Q., Li Y., Cheng, Y., Wang, F., Wei, J., Liu, Y., Zhang, C., Song, B., Yan, C., and Ansari, U. (2018). Numerical simulation of fracture reorientation during hydraulic fracturing in perforated horizontal well in shale reservoirs, Energy Sources, Part A: Recovery, Utilization, and Environmental Effects, 40(15), pp. 1807-1813.

DOI: $10.1080 / 15567036.2018 .1486920$.

[15] Zhou, X., Lian, Y., Wong, L., and Berto, F. (2018) Understanding the fracture behavior of brittle and ductile multiflawed rocks by uniaxial loading by digital image correlation, Engineering Fracture Mechanics, 199, pp. 438-460. DOI: 10.1016/j.engfracmech.2018.06.007.

[16] Yu, Y., Zhu, W., Li, L., Wei, C., Yan, B., and Li, S. (2019) Multi-fracture interactions during two-phase flow of oil and water in deformable tight sandstone oil reservoirs, Journal of Rock Mechanics and Geotechnical Engineering, 12, pp. 821-849. DOI: 10.1016/j.jrmge.2019.09.007.

[17] Zhang, H., Pu, C., and Sun, C. (2020) Study on the interaction between hydraulic fracture and natural fracture based on extended finite element method. Engineering Fracture Mechanics. 230, pp. 106981.

DOI: $10.1016 /$ j.engfracmech.2020.106981.

[18] Arash, D. (2009) Analysis of hydraulic fracture propagation in fractured reservoirs: an improved model for the interaction between induced and natural fractures, Doctoral Dissertation, University of Texas at Austin.

[19] Mahdi, H., and Kamy, S. (2016). XFEM-Based CZM for the Simulation of 3D Multiple-Cluster Hydraulic Fracturing in Quasi-Brittle Shale Formations, Rock Mechanics and Rock Engineering, 49, pp. 4731-4748.

DOI: 10.1007/s00603-016-1057-2.

[20] Ren, Q., Dong, Y., and Yu, T. (2009). Numerical modeling of concrete hydraulic fracturing with extended finite element method, Science in China Series E: Technological Sciences, 52(3), pp. 559-565.

DOI: $10.1007 / \mathrm{s} 11431-009-0058-8$.

[21] Renshaw, C., and Pollard, D. (1995). An experimentally verified criterion for propagation across unbounded frictional interfaces in brittle, linear elastic materials, International Journal of Rock Mechanics and Mining Sciences \& Geomechanics Abstracts, 32(3), pp. 237-249. DOI: 10.1016/0148-9062(94)00037-4.

[22] Zhang, G. M., Liu, H., Zhang, J., Wu, H., and Wang, X. (2010). Three-dimensional finite element simulation and parametric study for horizontal well hydraulic fracture, Journal of Petroleum Science \& Engineering, 72(3-4), pp. 310317. DOI: 10.1016/j.petrol.2010.03.032.

[23] Feng, Y., and Gray, K. E. (2017). Parameters controlling pressure and fracture behaviors in field injectivity tests: a numerical investigation using coupled flow and geomechanics model, Computers \& Geotechnics, 87, pp. 49-61. DOI: 10.1016/j.compgeo.2017.02.002.

[24] SIMULIA. (2016). Abaqus version 2016 analysis user's guide, Providence (RI,USA): Dassault Systèmes. 
[25] Benzeggagh, M. L., and Kenane, M. (1996). Measurement of mixed-mode delamination fracture toughness of unidirectional glass/epoxy composites with mixed-mode bending apparatus, Composites Science and Technology, 56(4), pp. 439-449. DOI: 10.1016/0266-3538(96)00005-X.

[26] Guo, T., Qu, Z., Gong, F., and Wang, X. (2017). Numerical Simulation of Hydraulic Fracture Propagation Guided by Single Radial Boreholes, Energies, 10, pp. 1680: 1-22. DOI: 10.3390/en10101680.

[27] Gong, D, Chen, J., Qu, Z., and Guo, T. (2018). Effect of Radial Well Guidance on Hydraulic Fracturing Crack Propagation Mechanism, Journal of Southwest Petroleum University (Science \& Technology Edition), 40(5), pp. 122130. (In Chinese) DOI: 10.11885/j.issn.1674-5086.2017.10.27.02.

[28] Qu, Z., Tian, Y., Li, J., Guo, T., Li, X., and Liu, X. (2017) Numerical simulation study on fracture extension and morphology of multi-cluster staged fracturing for horizontal wells, Journal of China University of Petroleum (Edition of Natural Science), 41(1), pp. 102-109. (In Chinese) DOI: 10.3969/j.issn.1673-5005.2017.01.013.

[29] Gong, D., Qu, Z., Li, J., Qu G., Cao, Y., and Guo, T. (2016) Extended finite element simulation of hydraulic fracture based on ABAQUS platform, Rock and Soil Mechanics, 37(5), pp. 1512-1520. (In Chinese)

DOI: $10.16285 /$ j.rsm.2016.05.036.

[30] Mahdi, H., and Sepehrnoori, K. (2015) Simulation of hydraulic fracturing in quasi-brittle shale formations using characterized cohesive layer: Stimulation controlling factors, Journal of Unconventional Oil and Gas Resources, 9, pp. 65-83. DOI: 10.1016/j.juogr.2014.10.001.

[31]Jiang, H., Chen, M., Zhang, G., Jin, Y., Zhao, Z., and Zhu, G. (2009). Impact of oriented peroration hydraulic fracture initiation and propagation, Chinese Journal of Rock Mechanics and Engineering, 28(7), pp. 1321-1326.

DOI: 10.3321/j.issn:1000-6915.2009.07.004.

[32] Fatahi, H., Hossain, M., and Fallahzadeh, S. (2016). Numerical simulation for the determination of hydraulic fracture initiation and breakdown pressure using distinct element method, Journal of Natural Gas Science and Engineering, 33, pp. 1219-1232. DOI: 10.1016/j.jngse.2016.03.029.

[33] Ishida, T., Chen, Q., Mizuta, Y., and Roegiers, J. (2004). Influence of Fluid Viscosity on the Hydraulic Fracturing Mechanism, Journal of Energy Resources Technology, 126(3), pp. 190-200. DOI: 10.1115/1.1791651. 